\title{
WestVirginiaUniversity
}

THE RESEARCH REPOSITORY @ WVU

Graduate Theses, Dissertations, and Problem Reports

2014

\section{Application of Neural Network Techniques to Downscale Precipitation}

Javad Rahimikollu

West Virginia University

Follow this and additional works at: https://researchrepository.wvu.edu/etd

\section{Recommended Citation}

Rahimikollu, Javad, "Application of Neural Network Techniques to Downscale Precipitation" (2014). Graduate Theses, Dissertations, and Problem Reports. 146.

https://researchrepository.wvu.edu/etd/146

This Thesis is protected by copyright and/or related rights. It has been brought to you by the The Research Repository @ WVU with permission from the rights-holder(s). You are free to use this Thesis in any way that is permitted by the copyright and related rights legislation that applies to your use. For other uses you must obtain permission from the rights-holder(s) directly, unless additional rights are indicated by a Creative Commons license in the record and/ or on the work itself. This Thesis has been accepted for inclusion in WVU Graduate Theses, Dissertations, and Problem Reports collection by an authorized administrator of The Research Repository @ WVU. For more information, please contact researchrepository@mail.wvu.edu. 


\title{
Application of Neural Network Techniques to Downscale Precipitation
}

\author{
Javad Rahimikollu
}

Thesis submitted to the Benjamin M. Statler College of Engineering and Mineral Resources at West Virginia University

in partial fulfillment of the requirements for the degree of

\author{
Master of Science in \\ Industrial Engineering \\ Rashpal S. Ahluwalia, Ph.D., Chair \\ Antar Jutla, Ph.D. \\ Robert C. Creese, Ph.D.
}

Department of Industrial and Management Systems Engineering

Morgantown, West Virginia

2014

Keyword: Neural Networks, Support Vector Regression, Downscaling, Climate Change, Precipitation Forecasting

Copyright 2014 Javad Rahimikollu 


\section{ABSTRACT \\ Application of Neural Network Techniques to Downscale Precipitation}

\section{Javad Rahimikollu}

Global climate change is a major area of concern to public and climate researchers. It impacts flooding, crop yields, water based diseases, etc. Significant effort has gone into developing climate models. Global climate models use a coarse grid of $300 \times 300 \mathrm{Km}^{2}$, while the resolution of interest for the hydrologist is $50 \times 50 \mathrm{Km}^{2}$.

Downscaling is the tool to map the large-scale global climate properties to a finer grid size in order to accurately predict climate variables such as precipitation. This study utilized Artificial Neural Networks (ANN) and Hybrid Support Vector Regression (HSVR) methods to predict precipitation at a finer grid, based on the data from a coarse grid. Precipitation data for three stations (Dhaka, Comilla and Mymesnsingh in Bangladesh) was utilized. For each model, the raw data was partitioned into training and test datasets. Based on the $\mathrm{R}^{2}$ values, the HSVR technique appears to be superior to other methods. 


\section{Table of Contents}

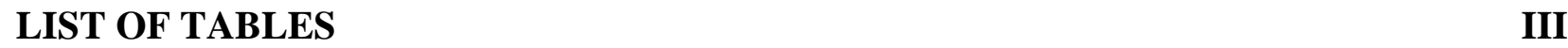

LIST OF FIGURES IV IV I I I I I I I I

LIST OF NOTATIONS L V V V

LIST OF ACRONYMS N VII

$\begin{array}{ll}\text { CHAPTER 1: INTRODUCTION } & 1\end{array}$

$\begin{array}{ll}1.1 \text { Literature Review } & 1\end{array}$

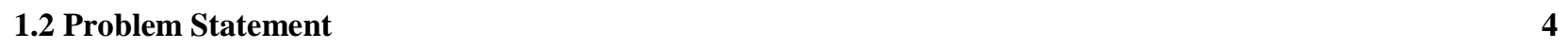

$\begin{array}{ll}\text { 1.3 Methodology } & 5\end{array}$

CHAPTER 2: DOWNSCALING METHODS 6

$\begin{array}{lc}2.1 \text { Linear Regression (LR) } & 6\end{array}$

$\begin{array}{ll}\text { 2.2 Artificial Neural Networks } & \mathbf{7}\end{array}$

$\begin{array}{ll}\text { 2.2.1 Neural Network structure } & 7\end{array}$

2.2.2 Artificial Neural Network Training $\quad 8$

$\begin{array}{ll}2.2 .3 \text { Over-fitting problem } & 10\end{array}$

2.3 Support Vector Regression (SVR)

$\begin{array}{ll}\text { 2.3.1 Non-linearmodels } & 13\end{array}$

2.4 Hybrid Support Vector Regression $\quad 13$

2.4.1 Particle Swarm Optimization $\quad 13$

2.4.2 Fitness criterion 14

CHAPTER 3: APPLICATION OF HSVR TO DOWNSCALE PRECIPITATION 17

$\begin{array}{ll}\text { 3.1 Data Description } & 17\end{array}$

3.2 Results and Analysis $\quad 19$

3.2.1 Comilla Station $\quad 20$

3.2.2 Dhaka Station 22

3.2.3 Mymensingh Station 23

3.2.4 Model for the features at surface level $\quad 24$ 


\section{List of Tables}

TABLE 1-LIST OF LARGE GRID FEATURES

TABLE 2-COMPARATIVE RESULTS FOR TEST DATA IN COMILLA STATION 21

TABLE 3 - COMPARATIVE RESULTS FOR TEST DATA IN DHAKA STATION 22

TABLE 4-COMPARATIVE RESULTS FOR TEST DATA IN MYMENSINGH STATION 24

TABLE 5-SURFACE LEVEL FEATURES

TABLE 6-COMPARATIVE RESULTS OF SURFACE FEATURES FOR COMILLA STATION 26

TABLE 7-COMPARATIVE RESULTS OF SURFACE FEATURES FOR DHAKA STATION 26

TABLE 8-COMPARATIVE RESULTS OF SURFACE FEATURES FOR MYMENSINGH STATION 27

TABLE 9- 500PA LARGE SCALE FEATURES

TABLE 10-COMPARATIVE RESULTS OF 500PA FEATURES FOR COMILLA STATION 28

TABLE 11-COMPARATIVE RESULTS OF 500PA FEATURES FOR DHAKA STATION 29

TABLE 12-COMPARATIVE RESULTS OF 500PA FEATURES FOR MYMENSINGH STATION 29

TABLE 13-850 LARGE SCALE FEATURES 30

TABLE 14-COMPARATIVE RESULTS OF 850PA FEATURES FOR COMILLA STATION 30

TABLE 15-COMPARATIVE RESULTS OF 850PA FEATURES FOR DHAKA STATION 31

TABLE 16-COMPARATIVE RESULTS OF 850 PA FEATURES FOR MYMENSINGH STATION 32 


\section{List of Figures}

FIGURE 1 - DOWNSCALING PROCESS

FIGURE 2-NEURAL NETWORK STRUCTURE $\quad 8$

FIGURE 3-HSVR ALGORITHM 16

FIGURE 4-THREE STATIONS (SOURCE: NATIONS ONLINE PROJECT) 20

FIGURE 5- MONTHLY OBSERVED AND DOWNSCALED PRECIPITATION FOR COMILLA STATION 21

FIGURE 6-MONTHLY OBSERVED AND DOWNSCALED PRECIPITATION FOR DHAKA CITY 23

FIGURE 7-MONTHLY OBSERVED AND DOWNSCALED PRECIPITATION FOR MYMENSINGH CITY 24 


\section{List of Notations}

\begin{tabular}{|c|c|}
\hline Notation & Description \\
\hline$i$ & Indexes unit in input layer or the feature number \\
\hline$j$ & Indexes unit in hidden layer \\
\hline net $_{j}$ & Scalar net activation of neuron $\mathrm{j}$ in hidden layer \\
\hline net $_{k}$ & Scalar net activation of neuron $\mathrm{k}$ in output layer \\
\hline $\mathrm{Nh}$ & Number of neurons in hidden layer \\
\hline $\mathrm{Nk}$ & Number of neurons in output layer \\
\hline$O_{i}$ & Output of neuron $\mathrm{i}$ in input layer \\
\hline$O_{j}$ & Output of neuron $\mathrm{j}$ in hidden layer \\
\hline$\delta_{k}$ & Sensitivity of neuron $\mathrm{k}$ at output layer \\
\hline$\delta_{j}$ & Sensitivity of neuron $\mathrm{j}$ at hidden layer \\
\hline$\eta$ & Learning rate \\
\hline$J$ & Error function in ANNs \\
\hline$R$ & Risk function \\
\hline$N$ & Overall Number of data points \\
\hline$x$ & Space for input pattern \\
\hline$y$ & Output vector \\
\hline$t$ & Target vector \\
\hline $\bar{t}$ & The average of target values \\
\hline$X N$ & Normalized data \\
\hline$b$ & Regression line bias term \\
\hline$w_{S V R}$ & Regression line weight vector \\
\hline$\epsilon$ & Acceptable deviation range \\
\hline$\zeta_{u}^{+}$ & Positive deviation from acceptable region for u-th pattern \\
\hline$\zeta_{\mathrm{u}}^{-}$ & Negative deviation from acceptable region for $\mathrm{u}$-th pattern \\
\hline $\mathrm{C}$ & Cost of not falling inside the SVR tube \\
\hline$\varphi$ & The kernel function \\
\hline$c_{1}$ & Self-cognitive constant \\
\hline $\mathrm{w}_{\mathrm{pso}}$ & The inertia weight \\
\hline$x_{l, d(\text { pbestl })}$ & Best experience of $l^{\text {th }}$ particle \\
\hline
\end{tabular}




\section{List of Notations (Cont'd)}

\begin{tabular}{|c|c|}
\hline$x_{l, d(\text { gbestl })}$ & Best experience of all particles \\
\hline$a_{1}, a_{2}$ & Randomly distributed uniform variables in $[0,1]$ \\
\hline$\sigma$ & The sigma value of kernel function \\
\hline$F_{i}$ & Feature i \\
\hline $\mathrm{n}$ & Number of features \\
\hline $\mathrm{u}$ & Unit index of $u^{\text {th }}$ pattern \\
\hline $\mathrm{v}$ & Unit index of $v^{\text {th }}$ pattern \\
\hline ite & Iteration number for PSO \\
\hline 1 & $l^{\text {th }}$ particle of Particle Swarm Optimization \\
\hline $\mathrm{d}$ & $d^{\text {th }}$ element of particle \\
\hline$\theta$ & Accepted Error for BP \\
\hline $\mathrm{r}$ & $r^{\text {th }}$ epoch in back propagation algorithm \\
\hline$W_{j i}$ & Weight for connection from neuron $\mathrm{i}$ to neuron $\mathrm{j}$ in hidden layer \\
\hline$W_{k j}$ & $\begin{array}{l}\text { Weight for connection from neuron } \mathrm{j} \text { in hidden layer to neuron } \mathrm{k} \text { in output } \\
\text { layer }\end{array}$ \\
\hline FIT & Fitness function \\
\hline$x p_{l, d}^{i t e}$ & $d^{t h}$ element of $l^{\text {th }}$ particle at iteration ite \\
\hline $\mathrm{D}$ & Dimension of feature space \\
\hline $\mathrm{Di}$ & Dimension of the population in PSO \\
\hline $\mathrm{P}$ & Number of selected features \\
\hline$R_{(a d j) t r}^{2}$ & Adjusted $R^{2}$ for train data \\
\hline$R_{(a d j) v a l}^{2}$ & Adjusted $R^{2}$ for validation data \\
\hline $\begin{array}{ll}\text { ite } \\
\text { id }\end{array}$ & Velocity of $d^{\text {th }}$ dimension of $l^{\text {th }}$ particle at iteration ite \\
\hline$x_{i u}$ & The amount of feature $i$ on $u t h$ pattern. \\
\hline$y_{u}$ & The amount of output for $u$ th pattern. \\
\hline$\beta_{i}$ & Regression coefficient for feature $i$ \\
\hline
\end{tabular}




\section{List of Acronyms}

\begin{tabular}{|l|l|}
\hline Acronym & Description \\
\hline SVR & Support Vector Regression \\
\hline HSVR & Hybrid Support Vector Regression \\
\hline ANNs & Artificial Neural Networks \\
\hline BP & Back Propagation \\
\hline GCMs & Global Climate Models \\
\hline RD & Regression Downscaling \\
\hline CCCSN & Canadian Climate Change Scenarios Network \\
\hline
\end{tabular}




\section{Chapter 1: Introduction}

\subsection{Literature Review}

Global climate change is a major area of concern to public and climate researchers. It impacts flooding, crop yields, water based diseases, etc. Significant effort has gone into developing climate models [Ojha et. al., 2010]. The scope of these models ranges from the entire globe to a small region. There are numerous parameters, such as wind speed, wind direction, atmospheric pressure, associated with modeling climate change. The impact of climate change on precipitation is of special concern to the hydrology community [Ojhaet.al., 2010].

Global Climate Models (GCMs) utilize the resolution of coarser than $2^{\circ}$ (few hundred kilometers) in latitude and longitude while the scale of interest for hydrologists is finer than this resolution. Therefore hydrology community defines downscaling as the process of linking the free atmosphere properties of GCMs outputs to predict local meteorological conditions (i.e precipitations and temperature) as shown in[Fowler et. al., 2007].

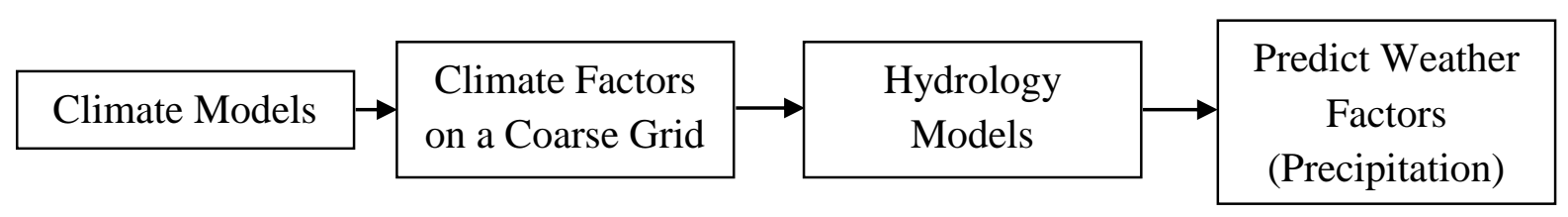

Figure 1 - Downscaling Process

Climate studies employ large scale free atmospheric variables to estimate climate changes. The Canadian Institute for Climate Studies (CICS) identified twenty six (26) free atmospheric variables for a land grid size of $300 \mathrm{~km}$ x $300 \mathrm{~km}$ [R.L. Wilby et. al, 2012]. These variables are capable of representing various earth segments; i.e. atmosphere land surface and humidity [Fowler et. al., 2007]. The main task of downscaling is to link the twenty six (26) free atmospheric 
variables as identified by the CICS to local climate variables such as precipitation [Grotch et. al, 1991].

One of the main downscaling approaches is Statistical Downscaling (SD).SD employs nonlinear functions to translate large scale Global Climate Models (GCM) features to sub-grid local variables [Girvetz et. al., 2009]. Because SD pertains to less computationally expensive techniques, it is widely preferred over other downscaling techniques in hydrological studies and has gained increasing attention in recent studies [Girvetz et. al., 2009]. SD techniques can be grouped in three main categories [Fowler et. al, 2007]:

○ Weather typing approaches;

o Stochastic weather generators;

○ Regression-based downscaling (RD) methods.

RD methods utilize statistical and machine learning methods to map features from a large grid to a local one to estimate a climate variable such as precipitation. Each of these methods encompasses a wide variety of techniques relying on a function representing a relation of atmospheric and local climate variables. This relation can be expressed as $y=f(x)$ where the fine resolution y is a function of atmospheric large scale factors $\mathrm{x}$ [Busuioc et. al., 2001].

The main regression based downscaling methods are: [Wibly and Dawson, 2012]

○ Linear Regression (LR)

○ Artificial Neural Networks (ANNs)

○ Support Vector Regression (SVR)

In many research studies, LR methods have been used for downscaling. Abaurrea and Asin (2005) utilized LR regression model to forecast a long term local daily precipitation in a climate change scenario in Spain using GCM as predictors. Huth (2002) applied LR to model daily precipitation. 
Huth (2005) used multiple linear regression to downscale precipitation in the summer at four stations in Czech Republic and compared with the result of some other techniques. Kidson and Thompson (1998) applied LR to predict daily and monthly precipitation over New Zealand for 1980-94.Tatliet. al. (2001) applied LR to downscale monthly precipitation in Turkey. Schoof and Pryor (2004) used LR to downscale daily and monthly precipitation in Indianapolis, IN, USA for two different seasons.

ANNs has been utilized to precipitation downscaling problem. Cannon and Whitfield (2002) used ANNs to downscale streamflow during recent decades in British Columbia, Canada and it was concluded that ANN outperforms stepwise linear regression. Cawleyet. al. (2003) applied a neural network based technique to describe precipitation downscaling in England. Dibike and Coulibaly (2006) used neural networks approach to downscale GCM output to predict daily precipitation in Quebec, Canada and a comparison showed that ANNs outperformed LR. Hall et. al. (1999) used ANNs to downscale daily precipitation in Dallas-Fort Worth. Olsson et. al. (2004) applied artificial neural network based downscaling method to forecast rainfall in southern Japan. Tolikaet. al. (2007) used ANNs based downscaling technique to predict seasonal precipitation and rain days for specific sites in Greece.

SVR is also applied in recent studies. Lima et. al. (2012) applied SVR to precipitation downscaling problem and concluded that SVR outperform ANNs. Chen et. al. (2010) applied to downscale daily precipitation in Shih-Men Reservoir basin of Taiwan. Tripathi et. al. (2006) applied SVR to downscaling problem over India and it was shown that SVR outperforms ANNs in these stations. 
Recently, linear regression is not used due to nonlinear relationship between the independent variables. ANN and SVR have been utilized by hydrologists to estimate precipitation. These methods are preferred due to their ability to handle nonlinear data. Recently, Hybrid Support Vector Regression (HSVR) was developed by [Lin et.al, 2008]. HSVR method shows a better performance compared to SVR, however HSVR has not been applied to the precipitation downscaling studies.

\subsection{Problem Statement}

The focus of this study is to perform the following task:

o Apply the following techniques to the downscaling problem:

- Linear Regression (LR)

- Artificial Neural Networks (ANN)

- Hybrid Support Vector Regression (HSVR)

- Predict precipitation as a function of the twenty six (26) atmospheric variables as identified by Canadian Climate Change Scenarios Network (CCCSN).

- Compare HSVR prediction results obtained by LR, ANN methods and recommend the better technique. 


\subsection{Methodology}

Methodology for conducting the above study is as follows:

- Conduct literature review in the area of precipitation on use of ANNs, LR and HSVR to estimate precipitation.

- Apply ANNs, LR and HSVR to precipitation estimation.

- Gather benchmark data from literature and industry archives.

- Compare the results estimated by the three methods. 


\section{Chapter 2: Downscaling Methods}

Regression models are used to identify relationships between local variables and free atmospheric variables as predictors [Giorgi, et al, 2001]. Multi variable regression is the simplest form of regression technique. It is applied widely to predict local features such as temperature and precipitation [Hellstrom, et.al, 2001]. Techniques such as Artificial Neural Networks (ANNs) [Tatliet. al, 2004] and Support Vector Regression (SVR)[Chen, et.al, 2010] are also utilized to map large scale variables to fine scale climate variables using nonlinear functions. ANN and SVR offer natural flexibility and are capable to identify nonlinear patterns. These techniques are preferred over other methods by the climate study community [Chen, et.al, 2010], however they have some disadvantages. ANNs can fall inside a local minima and the model complexity can be a computationally expensive process [Suykens et.al, 2001]. Similarly, due to complexity of the parameter space, determining the appropriate SVR parameters is difficult [Boardman, et al, 2006].Beside the aforementioned problems, all regression techniques require identification of predictor variable [Li, et.al, 2008]. A specific variable may not be significant for a location, but highly significant for another location. The HSVR method was developed by [Li, et.al, 2008] to automate the task of feature selection. Brief overview of LR, ANN, SVR and HSVR is provided below.

\subsection{Linear Regression (LR)}

LR is one of the oldest and simplest tools to analyze the data. A LR model is described in Equation (1):

$$
y_{1}=\beta_{0}+\beta_{1} x_{11}+\beta_{2} x_{21}+\beta_{3} x_{31}+\beta_{4} x_{41}+\cdots+\beta_{n} x_{n 1}+\varepsilon
$$


Least square method determines the parameters in regression line using Equation (2). $\varepsilon$ is the error term which is normally distributed.

$$
\hat{\beta}=\left(X^{T} X\right)^{-1} X^{T} Y
$$

The matrices $\mathrm{X}$ and vector $\mathrm{Y}$ can be defined as Equations (3) and (4) show:

$$
\begin{gathered}
X=\left[\begin{array}{ccc}
1 & x_{11} \cdots & x_{n 1} \\
\vdots & \ddots & \vdots \\
1 & x_{1} \cdots & x_{n N}
\end{array}\right] \\
Y=\left[\begin{array}{c}
y_{1} \\
y_{2} \\
\vdots \\
y_{N}
\end{array}\right]
\end{gathered}
$$

In stepwise regression, several regression models are used to choose the variables that have the most impact on the model based on the $\mathrm{R}^{2}$ value. This procedure can be automated using three different approaches: 1) Forward selection, 2) Backward elimination, and 3) Bi-directional elimination. [Ralston et. al, 1960]

\subsection{Artificial Neural Networks}

\subsubsection{Neural Network structure}

Artificial Neural Networks (ANNs) are mathematical models inspired by human brain nerve system. Neural Networks in human brain consists of nerve cells. Each nerve cell is connected to other nerve cells [Yegnanarayana, 2004]. Similar to the human neurons, ANNs consist of neurons which are connected to the neurons of previous or next layer. A weight is assigned to each connection. The output of each neuron is a function of these weights [Duda, et. al,2012]. Each layer has a number of 'nodes'. Figure 2 shows a neural network structure. Each node contains an 'activation function'. Activation function specifies the output of a neuron. Different activation 
functions can be utilized in a network. Some common activation functions are sigmoid, tangent and linear. Equations (5), (6) and (7)describe these functions [Duda, et. al, 2012]:

$$
\begin{array}{ll}
\text { Sigmoid: } f(x)=\frac{1}{1+e^{-x}} ; & 0<f(x)<1 \\
\text { Tangent: } f(x)=\frac{e^{-x}-e^{-x}}{e^{-x}+e^{-x}}, & 0<f(x)<1
\end{array}
$$

$$
\text { Linear: } f(x)=x
$$

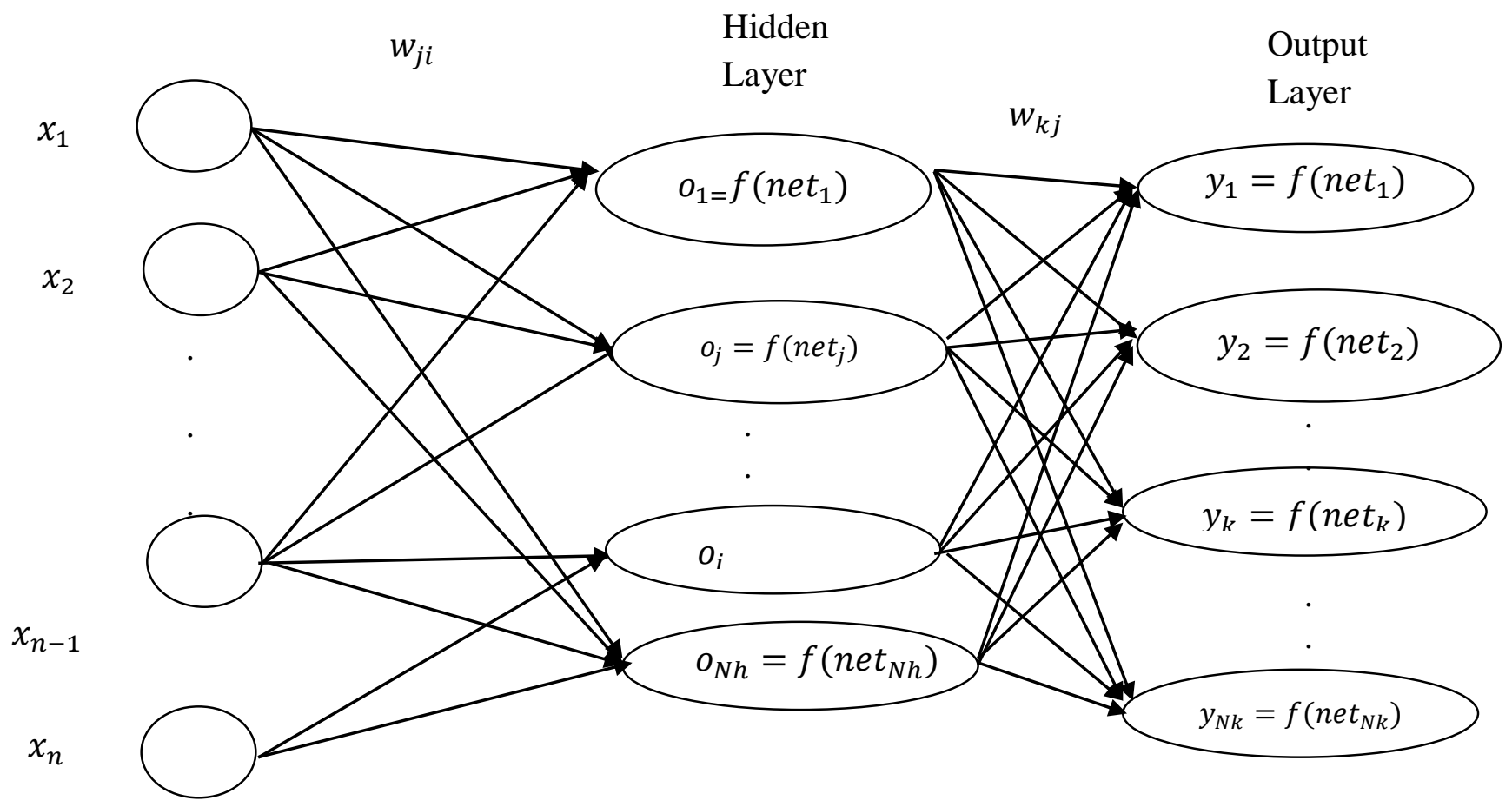

Figure 2-Neural Network Structure

\subsubsection{Artificial Neural Network Training}

The main goal of neural network is to analyze the data and to adjust weights in a process called "network training". Back Propagation Algorithm (BPA) is widely applied to train neural networks. Rumelhart (2002) proposed BPA to find the optimal values of connection weights. This method consists of two main steps: 


\section{Feed Forward}

In this step, the output of each neuron of hidden layer will be obtained using Equation (9).

$$
\begin{aligned}
\text { net }_{j} & =\sum_{i=0}^{n} x_{i} w_{j i} \\
o_{j} & =f\left(\text { net }_{j}\right) \\
\text { net }_{k} & =\sum_{j=0}^{n_{h}} O_{j} w_{k j}
\end{aligned}
$$

Where $w_{j i}$ is the weight of connection between neuron $\mathrm{i}$ to neuron $\mathrm{j}$ at hidden layer. net $_{j}$ and $n e t_{j k}$ represent the scalar net activation of neuron $\mathrm{j}$ and $\mathrm{k}$ in hidden layer and output layer, respectively. $O_{j}$ also shows the output of neuron $\mathrm{j}$ in the hidden layer.

\section{Feed Backward}

Finally, the output from the output layer is calculated as shown in Equation (11):

$$
y_{k}=f\left(\text { net }_{k}\right)
$$

In this step, the error of the network is back propagated from output layer to input layer. According to Equation (12), sensitivity of neuron $\mathrm{k}$ at output layer $\left(\delta_{\mathrm{k}}\right)$ is calculated for each output node:

$$
\delta_{k}=y_{k}\left(1-y_{k}\right)\left(y_{k}-t_{k}\right)
$$

According to Duda (2012), sensitivity of neuron $\mathrm{j}$ at hidden layer $\left(\delta_{\mathrm{j}}\right)$ is calculated for each node in hidden layer: 


$$
\delta_{j}=\mathrm{O}_{j}\left(1-O_{j}\right) \sum_{k=1}^{N k} \delta_{k} w_{j k}
$$

Cost function J is calculated by Equation (14). Based on Equation(11), $\mathrm{y}_{\mathrm{k}}$ is a function of vector $\mathrm{w}$, therefore $\mathrm{J}$ will be the function of $\mathrm{w}_{\mathrm{kj}}$ and $\mathrm{w}_{\mathrm{ji}}, \mathrm{k}=1, \ldots, \mathrm{Nk} ; \mathrm{j}=1, \ldots, \mathrm{Nh}$; and $\mathrm{i}=1, \ldots, \mathrm{n}$.

$$
J=\frac{1}{2} \sum\left(y_{k}-t_{k}\right)^{2}
$$

The back propagation algorithm can be summarized as follows [Duda, 2012]:

\section{Back Propagation Algorithm}

1. Initializew, $\eta, r=0$

2. Do $r \leftarrow r+1$ (Update epoch)

3. $u \leftarrow 0 ; \Delta w_{i j} \leftarrow 0 ; \Delta w_{k j} \leftarrow 0$

4. Do $u \leftarrow u+1$

5. $x^{m} \leftarrow$ select pattern

6. $\Delta w_{i j} \leftarrow \Delta w_{i j}+\eta \delta_{j} x_{i} ; \Delta w_{k j} \leftarrow \Delta w_{k j}+\eta \delta_{k} y_{j}$

7. Until $u=N$

8. $\quad w_{i j} \leftarrow w_{i j}+\Delta w_{i j} ; w_{k j} \leftarrow w_{k j}+\Delta w_{k j}$

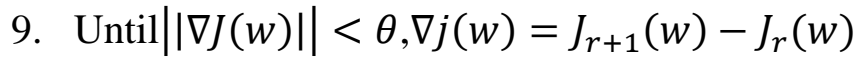

10. Return $w$

\subsubsection{Over-fitting problem}

Over-fitting problem occurs when the training data error is much less than validation data error. In this condition, neural networks lack the generalization power and predicting the results of new data is off target. To avoid such a problem, the following action can be taken: 
Cross Validation: Data is divided in three sets: Training, validation and testing. The algorithm uses a certain portion of data as a training data. After each training process, the validation data is used to test the performance of the model. After some numbers of failures in validation data sets, the algorithm stops the training process. The model parameters can be estimated, i.e. number of nodes in the hidden layer [Duda, et. al, 2012].

\subsection{Support Vector Regression (SVR)}

Suppose $\left\{\mathrm{x}_{\mathrm{u}}, \mathrm{t}_{\mathrm{u}}\right\}$ isthe given data where $\mathrm{x}_{\mathrm{u}} \in \mathrm{R}^{\mathrm{m}}$ and $\mathrm{t}_{\mathrm{u}} \in \mathrm{R}$. The goal is to find a regression line that maps $\mathrm{x}_{\mathrm{u}}$ to $t_{\mathrm{u}}$, such that the points fall inside the predefined tube. For a LR problem where $y_{u}=w^{T} x+b, w_{S V R}$ is the weight of $x$ and $b$ is the bias term, the accepted region of each pointt $_{u}$ is $\left\{y_{u}-\epsilon, y_{u}+\epsilon\right\}$. The value of $\epsilon$ can be selected by trial and error.

Vapnik (2000) proposed a function which is called $\epsilon$ intensive loss function to formulate the problem as shown in Equation (15):

$$
L_{\epsilon}\left(t_{u}, y_{u}\right)=\left\{\begin{array}{lr}
0 & \left|\mathrm{t}_{\mathrm{u}}-\mathrm{y}_{\mathrm{u}}\right|<\epsilon \\
\left|t_{u}-y_{u}\right|-\epsilon & \text { otherwise }
\end{array} \forall_{u}\right.
$$

Equation (16)shows the deviation from tube for $\mathrm{u}^{\text {th }}$ point. Equations (17) and (18)represent the deviation from different side of the tube.

$$
\begin{array}{ll}
\zeta_{u}=\left|t_{u}-y_{u}\right|-\epsilon & \forall_{u} \\
\zeta_{u}^{+}=t_{u}-y_{u}-\epsilon & \forall_{u} \\
\zeta_{u}^{-}=y_{u}-t_{u}-\epsilon & \forall_{u}
\end{array}
$$

A data point can be in three possible areas: 
1) If data point falls to the left side of the tube, $\zeta_{u}^{+}$will be positive, $\zeta_{u}^{-}$will be zero and $L_{\in}\left(t_{u}, y_{u}\right)=\zeta_{u}^{+}$.

2) If data point falls to the right side of the tube, $\zeta_{u}^{-}$will be positive, $\zeta_{u}^{+}$will be zero $\operatorname{and} L_{\epsilon}\left(t_{u}, y_{u}\right)=\zeta_{u}^{-}$.

3) If data point falls inside the tube, both $\zeta_{u}^{+}$and $\zeta_{u}^{-}$will be zero and $L_{\epsilon}\left(t_{u}, y_{u}\right)=0$.

We can conclude that $\zeta_{\mathrm{u}}^{+}$and $\zeta_{\mathrm{u}}^{-}$cannot be simultaneously positive since the data can only be in one of the areas and $\mathrm{L}_{\epsilon}\left(\mathrm{t}_{\mathrm{u}}, \mathrm{y}_{\mathrm{u}}\right)=\zeta_{\mathrm{u}}^{+}+\zeta_{\mathrm{u}}^{-}$. The goal is to find regression line such that the data points fall inside the tube or do not fall in left or right area. To do so, a risk function is defined as follows based on equation (19):

$$
R=\frac{1}{N} \sum_{u=1}^{N} L_{\epsilon}\left(x_{u}, y_{u}\right)=\frac{1}{N} \sum_{u=1}^{N}\left(\zeta_{u}^{+}+\zeta_{u}^{-}\right)
$$

The weightw $\mathrm{SVR}_{\mathrm{R}}$ indicates the complexity of the linear model. To find a simple and flat function without over-fitting, $|\mathrm{w}|$ should beminimized.Minimizing $|\mathrm{w}|$ is equivalent to minimizing $\frac{1}{2} \mathrm{~W}_{\mathrm{SVR}}^{\mathrm{T}} \mathrm{W}_{\mathrm{SVR}}$. Equations (21) and (22) represent the boundary of accepted region. By adding this term to our risk function an overall cost function can be obtained. Details of SVR are provided in [Vapnik, 2000].

$$
\min z=\frac{1}{2} w_{S V R}^{T} w_{S V R}+c \sum_{i=1}^{N}\left(\zeta_{u}^{+}+\zeta_{u}^{-}\right)
$$

Subject To:

$$
t_{u}-y_{u}<\epsilon+\zeta_{u}^{+} \quad \forall_{u}
$$




$$
\begin{array}{lr}
-\epsilon-\zeta_{u}^{-}<t_{u}-y_{u} \forall_{u} & \\
\zeta_{u}^{+}>0 & \forall_{u} \\
\zeta_{u}^{-}>0 & \forall_{u}
\end{array}
$$

\subsubsection{Non-linearmodels}

SVR exploits a kernel function to map $x_{u} \in R^{n}$ to higher dimensional feature space where theoretically exists a linear function $\mathrm{f}$ to formulate $\mathrm{y}$ as a function of input data $\mathrm{x}$ [Duda et.al, 2012].

The regression function can be written as Equation (25):

$$
y=f(x)=w_{S V R} \varphi(x)+b \quad \forall_{u}
$$

The kernel function can is defined by Equation (26):

$$
\varphi\left(x_{u}, x_{v}\right)=\exp \left(-\frac{1}{2 \sigma^{2}}|| x_{u}-x_{v}||^{2}\right) \quad \forall_{u}
$$

$x_{u}$ and $x_{v}$ are all possible combinations of the existing data points. The value of $\sigma$ is user identified. Using trial and error, one can obtain the value of the $\sigma$ in a time consuming process.

\subsection{Hybrid Support Vector Regression}

\subsubsection{Particle Swarm Optimization}

Particle swarm optimization (PSO) is an intelligent algorithm developed by [Eberhart, et al, 1995]. The PSO can be presented as follows:

$$
V_{l d}^{i t e}=w_{p s o} \cdot V_{l d}^{i t e-1}+c_{1} \cdot a_{1}\left(x p_{l d}^{i t e}-x_{l, d(p b e s t l)}\right)+c_{2} \cdot a_{2} \cdot\left(x p_{l, d}^{i t e}-x p_{l, d(g b e s t)}\right)
$$




$$
x p_{l, d}^{i t e+1}=x p_{l, d}^{i t e}+V_{l, d}^{i t e+1}
$$

PSO algorithm generates a random population in Di-dimensional search space. Particles are moving from their current position $\mathrm{xp}_{\mathrm{l}, \mathrm{d}}^{\text {ite }}$ in the directionof the velocity vector $\mathrm{V}_{\mathrm{l}, \mathrm{d}}^{\text {ite }}$ according to Equation (28). Particle's position and velocity are changing during the process until a termination criterion has been met.

\subsubsection{Fitness criterion}

FIT is the fitness criterion to optimize the HSVR. After obtaining adjusted $\mathrm{R}^{2}$, as in Equation (30), FIT is used to represent the model performance as in Equation (31). Using this fitness criterion, model one can increase the $\mathrm{R}^{2}$ for train data and the validation data. $\mathrm{R}^{2}$ can be represented as follows [Carpenter, 1960]:

$$
\begin{gathered}
R^{2}=1-\frac{\sum\left(t_{u}-y_{u}\right)^{2}}{\sum\left(t_{u}-\bar{t}\right)^{2}} \forall_{u} \\
R_{\text {adjusted }}^{2}=1-\frac{\left(1-R^{2}\right)(N-1)}{N-p-1} \forall_{u} \\
F I T=R_{(a d j) V a l}^{2} \forall_{u}
\end{gathered}
$$

To tune SVR parameters using PSO, a solution representation is designed as follows. The model is an extension of work done by [Lin et al, 2008]. The main extension of the method is the fitness function shown in Equation (32). In the previous HSVR model, $\mathrm{R}^{2}$ for validation data was used to optimize SVR. The optimization problem is described as:

$$
\operatorname{Max} F I T=g\left(C, \sigma, F_{i}\right) \forall_{i}=1 . .26
$$


Subject to:

$$
\begin{gathered}
C<1000 \\
\sigma<10 \\
F_{i}=0,1 ; \mathrm{C}, \sigma>0 \quad \forall_{i}=1 . \ldots 26
\end{gathered}
$$

Function $\mathrm{g}$ is the fitness function. The first two parameters are SVR parameters. C is the cost and $\sigma$ is the sigma value of kernel function. $F_{\mathrm{i}}$ is the feature selection variable. This variable represents the importance of a feature in the model. A value of one indicates the given feature is important and a value of zero indicates that the given feature is not important. The HSVR algorithm is as follows:

Step1: Initialize the solution randomly: Each variable will be randomized on a predefined range.

Step2: After acquiring the solution, algorithm will run the SVR. This will result in a fitness function value.

Step3: PSO will update velocity and position based on the fitness function.

Step4: Algorithm will stop after meeting the maximum number of iterations. The number of iterations for this problem is 100. A flowchart of the HSVR algorithm is shown in Figure 3. 


\section{Generate Initial Population}

\section{h}

\section{Evaluate the Fitness Function on each member of population}

If the Fitness for a particle is better than the best local Fitness for particle :Update Local Best

$$
\downarrow
$$

If the Fitness for a particle is better than the Global Fitness for particle: Update Global Best

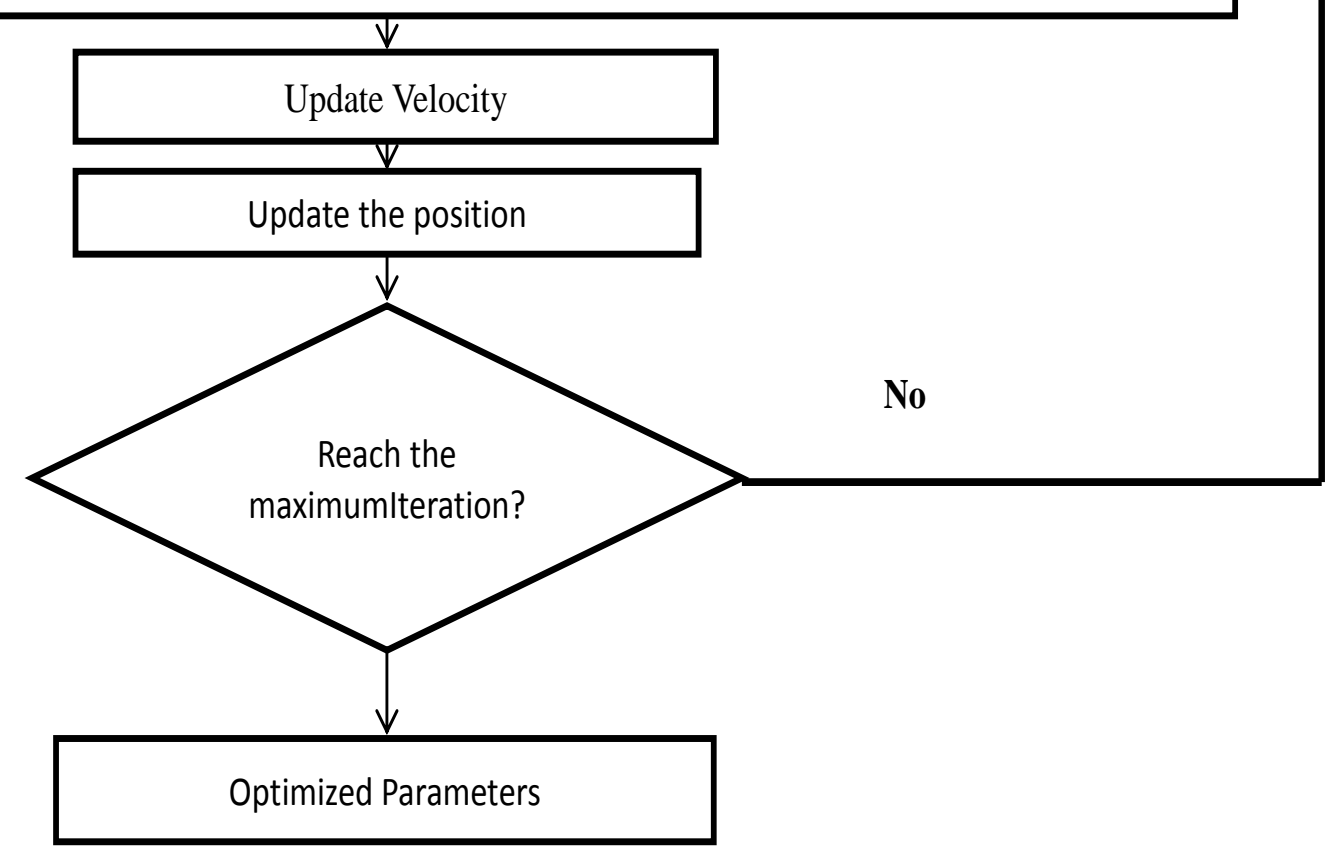

Figure 3-HSVR algorithm 


\section{Chapter 3: Application of HSVR to Downscale Precipitation}

\subsection{Data Description}

This study utilizes the following four datasets:

1. Data on 26 free atmospheric variables was obtained from http://www.cccsn.ec.gc.ca as shown in Table 1. This data uses large scale grid of size $300 \mathrm{~km}$ x $300 \mathrm{~km}$

2. Monthly Precipitation data for Comilla, Bangladesh (The data ranges from 1961 to 2001)

3. Monthly Precipitation data for Dhaka, Bangladesh (The data ranges from 1961 to 2001)

4. Monthly Precipitation data for Mymensingh, Bangladesh (The data ranges from 1961 to 2001)

5. Each of the features has different scales. To prepare the data for analysis, they need to be normalized using Equation (36). After the analysis, they will be un-normalized using Equation (37) as follows:

$$
\begin{gathered}
X N=2 * \frac{x-\min (x)}{\max (x)-\min (x)}-1 \\
x=\frac{(X N+1)(\max (x)-\min (x))}{2}+\min (x)
\end{gathered}
$$


Table 1-List of large grid features

\begin{tabular}{|c|c|c|}
\hline Feature Number & Feature & Description \\
\hline 1 & Temp & Mean temperature at $2 \mathrm{~m}$ \\
\hline 2 & MSLP & Mean sea level pressure \\
\hline 3 & $\mathrm{H} 850$ & 850 hPageopotential heights \\
\hline 4 & H500 & 500 hPageopotential heights \\
\hline 5 & USUR & Near surface westerly wind \\
\hline 6 & U850 & Westerly wind at $850 \mathrm{pa}$ \\
\hline 7 & U500 & Westerly wind at $500 \mathrm{pa}$ \\
\hline 8 & VSUR & Near surface southerly wind \\
\hline 9 & V850 & Southerly wind at $850 \mathrm{pa}$ \\
\hline 10 & V500 & Southerly wind at $500 \mathrm{pa}$ \\
\hline 11 & FSUR & Near surface wind strength \\
\hline 12 & F850 & Wind strength at $850 \mathrm{pa}$ \\
\hline 13 & F500 & Wind strength $500 \mathrm{pa}$ \\
\hline 14 & ZSUR & Near surface vorticity \\
\hline 15 & $\mathrm{Z850}$ & Vorticity at $850 \mathrm{pa}$ \\
\hline 16 & $\mathrm{Z500}$ & Vorticity at $500 \mathrm{pa}$ \\
\hline 17 & DSUR & Near surface divergence \\
\hline 18 & D850 & Divergence at $850 \mathrm{pa}$ \\
\hline 19 & D500 & Divergence at $500 \mathrm{pa}$ \\
\hline 20 & QSUR & Near surface specific humidity \\
\hline 21 & Q850 & Specific humidity at $850 \mathrm{pa}$ \\
\hline 22 & Q500 & Specific humidity at $500 \mathrm{pa}$ \\
\hline 23 & RSUR & Near surface relative humidity \\
\hline 24 & $\mathrm{R} 850$ & Relative humidity at $850 \mathrm{pa}$ \\
\hline 25 & R500 & Relative humidity at $500 \mathrm{pa}$ \\
\hline 26 & Temp & Mean Temperature at $2 \mathrm{~m}$ \\
\hline
\end{tabular}




\subsection{Results and Analysis}

The SVR was applied to data for Comilla, Dhaka and Mymensingh cities in Bangladesh using MATLAB software and LibSVM toolbox. To implement Artificial Neural Network a demo version of commercial Dtreg software [Sherrod, Phil, 2014] was used. The data set was partitioned in three different sets: calibration, validation and testing. The percentage of each portion of data is 70, 20 and 10, respectively. The maximum iteration for PSO to train this data was determined as 100. Observed precipitation and NCEP data for Comilla, Dhaka and Mymensingh cities were used to model calibration and validation. Three measurements of Bias, RMSE and $\mathrm{R}_{(\text {adj) }}^{2}$ is used to compare the results of each technique. Figure 4 displays the location of each city in the map. 


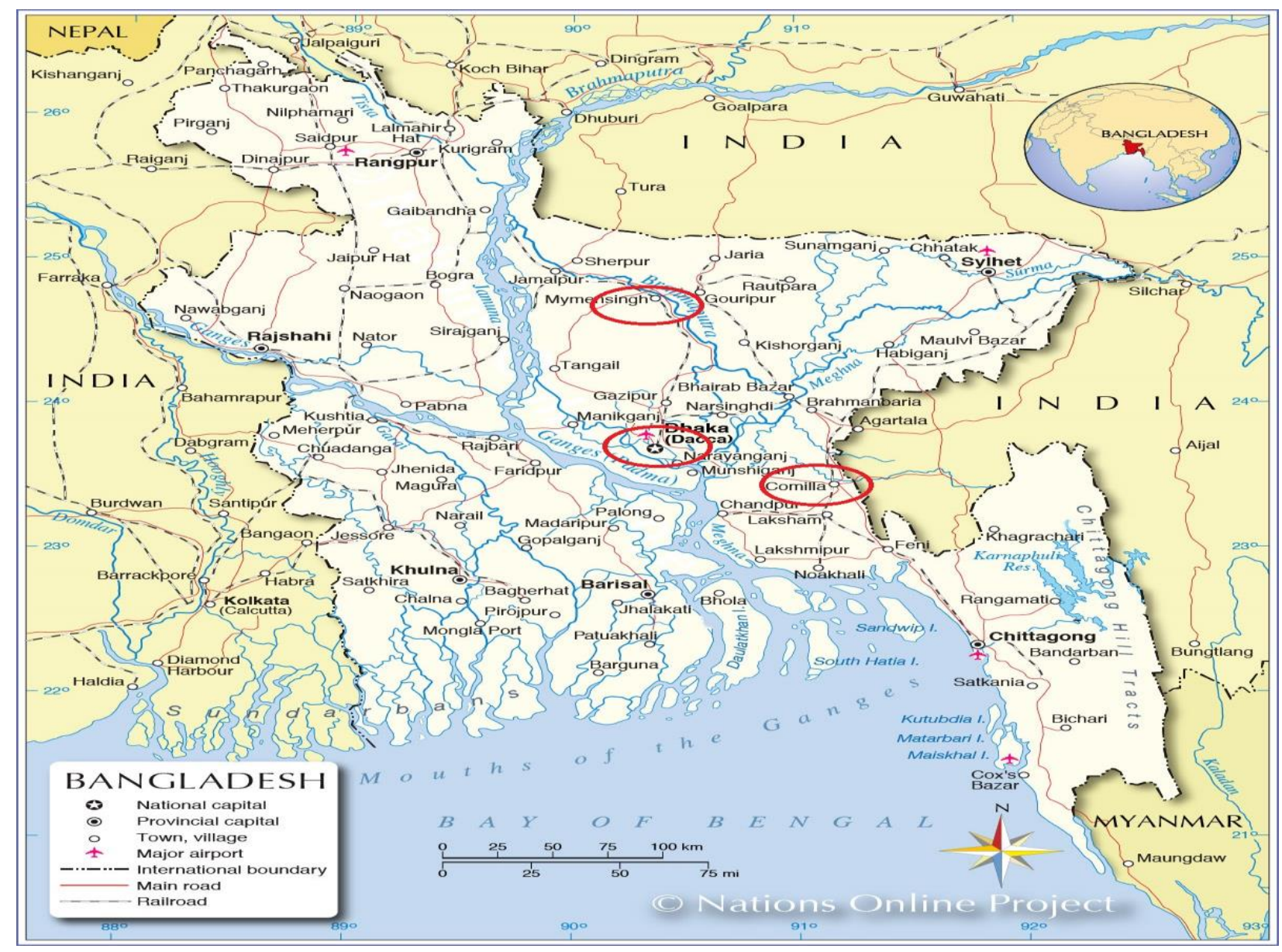

Figure 4-Three Stations (Source: Nations Online Project)

\subsubsection{Comilla Station}

The Comilla station is located at $23^{\circ} 27^{\prime} 20^{\prime \prime} \mathrm{N}$ latitudes and $91^{\circ} 10^{\prime} 58^{\prime \prime}$ E longitudes in Bengal delta. To construct the model, the NCEP data was trained for the period of 1961-2001 to find a link between large scale atmospheric variables and the local precipitation in Comilla station. Using stepwise regression, the following equation was obtained:

$$
y=-0.53+0.19 F_{7}+0.16 F_{17}+0.16 F_{13}+0.31 F_{11}+0.16 F_{5}-0.16 F_{10} .
$$


The optimum number of hidden neurons of 12 was found for ANNs based on validation data on the variables selected in stepwise regression method. $\epsilon=.001, C=83.63$ and $\sigma=$ 0.63 was found as optimal setting for SVR.

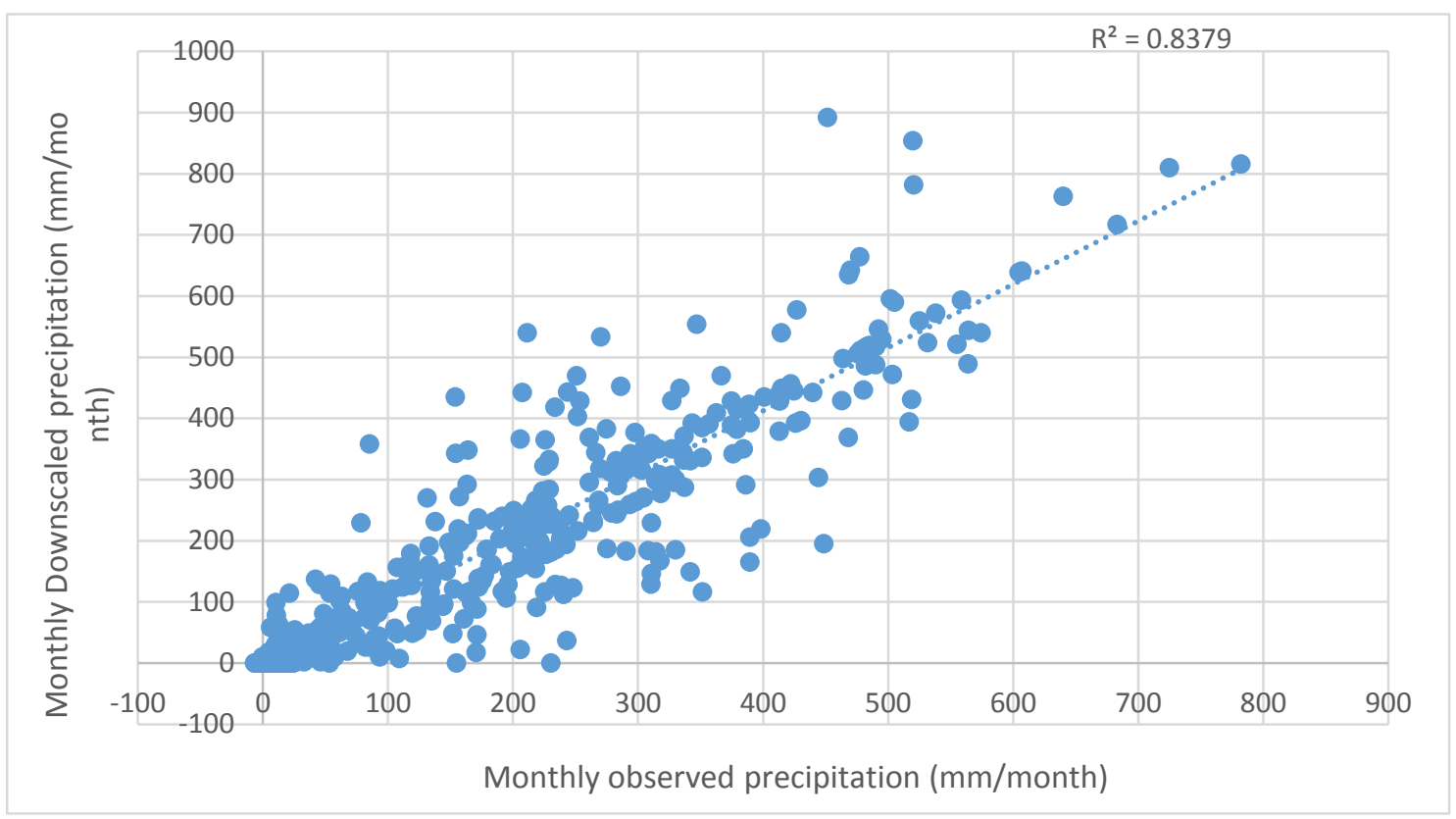

Figure 5- Monthly observed and downscaled precipitation for Comilla station

Table 2-Comparative results for test data in Comilla station

\begin{tabular}{|c|c|c|c|}
\cline { 2 - 4 } \multicolumn{1}{c|}{} & LR & ANN & HSVR \\
\hline R2 & 0.700 & 0.660 & 0.780 \\
\hline R2(adj) & 0.650 & 0.600 & 0.740 \\
\hline Bias & 1448 & 1592 & 1195 \\
\hline RMSE & 151 & 163.170 & 132.910 \\
\hline
\end{tabular}

Figure 5 demonstrates the acceptable performance of HSVR in downscaling GCM outputs to precipitation in Comilla station. Table 2 represents the results for test data which is a good indicator for generalization power of the HSVR which is better compared to other techniques. 


\subsubsection{Dhaka Station}

The Dhaka station is located at $23.7000^{\circ} \mathrm{N}$ latitudes and $90.3750^{\circ} \mathrm{E}$ longitude. Similar to Comilla station, the NCEP data was trained for the period of 1961-2001 to seek out a link between large scale atmospheric variables and the local precipitation in Dhaka station. The optimum number of hidden neurons is 5in this station. The optimum setting for SVR was obtained as $\epsilon=$ $.001, C=99.3745$ and $\sigma=0.19$.

Equation (39) was obtained using stepwise regression for this station. Figure 6 represents the suitable performance of the HSVR method and compares the results of HSVR with previous methods in Dhaka station.

$$
y=-0.54+0.36 F_{2}-0.2 F_{23}-0.11 F_{19}+0.08 F_{13}+\varepsilon
$$

Table 3 represents the results for test data for Dhaka station showing better performance of HSVR compared to other techniques.

Table 3 - Comparative results for test data in Dhaka station

\begin{tabular}{|c|c|c|c|}
\cline { 2 - 4 } \multicolumn{1}{c|}{} & LR & ANN & HSVR \\
\hline R2 & 0.622 & 0.613 & 0.673 \\
\hline R2(adj) & 0.582 & 0.573 & 0.638 \\
\hline Bias & 453.770 & 451.820 & 406.950 \\
\hline RMSE & 98.700 & 100.180 & 91.210 \\
\hline
\end{tabular}




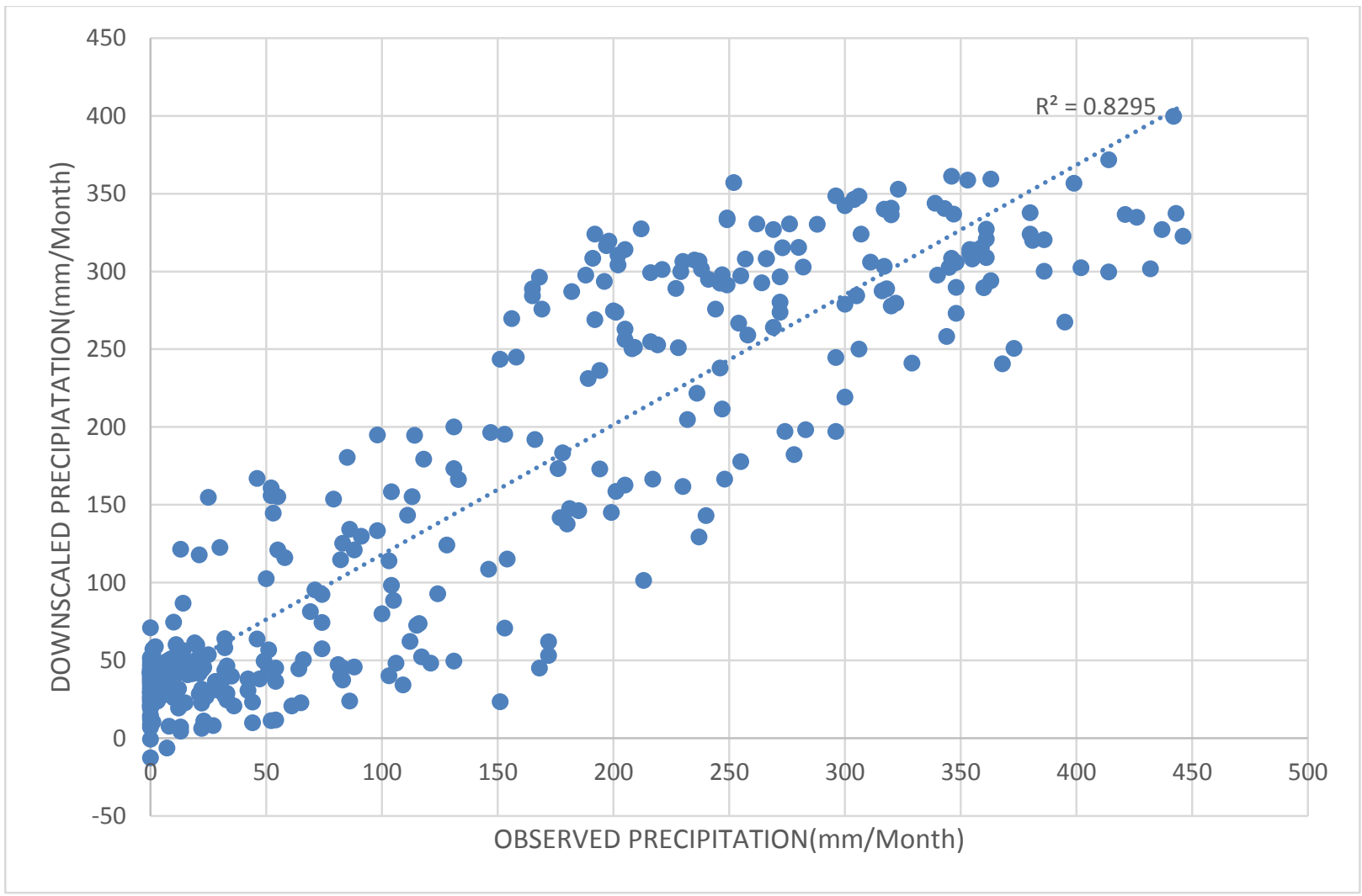

Figure 6-Monthly observed and downscaled precipitation for Dhaka City

\subsubsection{Mymensingh Station}

Mymensingh station is located at $24.7539^{\circ} \mathrm{N}$ latitude and $90.4031^{\circ} \mathrm{E}$ longitudes. Similar to other stations to build the model, the NCEP data was used to build the model for the period of 1961-2001in Mymensingh station (Figure 7). In this station, table 4 shows that HSVR outperforms previous techniques. The optimum number of hidden neurons is 4 in this station and optimum setting for SVR is $\epsilon=.001, C=89.2013$ and $\sigma=0.3213$. After getting the model on the period of 1961-2001.Table 4 compares HSVR with previous methods in this station. Equation (40) shows the coefficients obtained using stepwise regression:

$$
y=-0.58+0.06 F_{7}+0.13 F_{13}-0.59 F_{21}-0.53 F_{10}+0.20 F_{26}-0.08 F_{8}+0.71 F_{11}+\varepsilon
$$




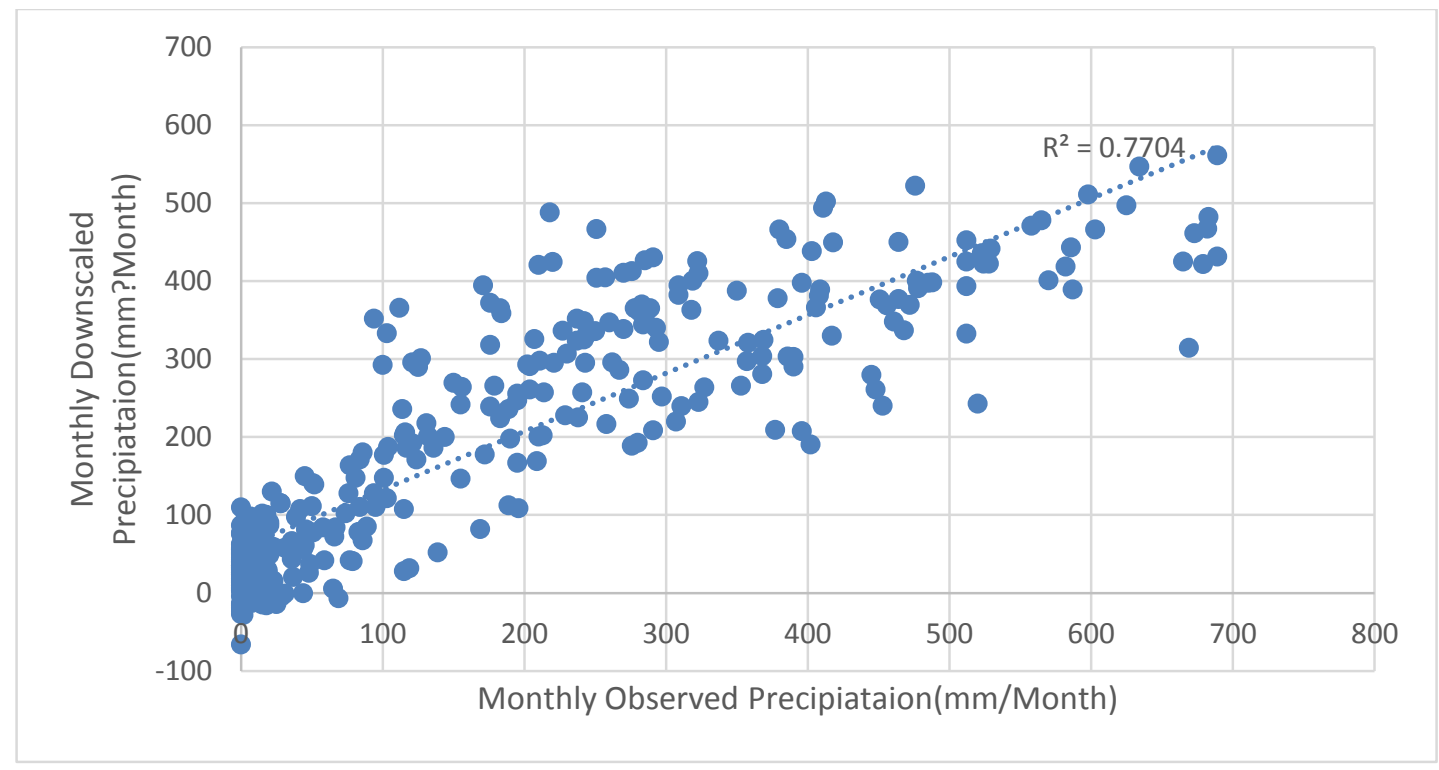

Figure 7-Monthly observed and downscaled precipitation for Mymensingh City

Table 4-Comparative results for test data in Mymensingh station

\begin{tabular}{|c|c|c|c|}
\cline { 2 - 4 } \multicolumn{1}{c|}{} & LR & ANN & HSVR \\
\hline R2 & 0.640 & 0.720 & 0.770 \\
\hline R2(adj) & 0.560 & 0.660 & 0.720 \\
\hline Bias & 669.201 & 892.742 & 453.794 \\
\hline RMSE & 25.870 & 29.880 & 21.300 \\
\hline
\end{tabular}

\subsubsection{Model for the features at surface level}

In this section, large scale features of Table 4 are grouped based on the level of the feature: Surface level, 500pa and 850 pa.

Table 5 represents the surface level features. In this section, these features are used to downscale precipitation in three stations of Dhaka, Mymensingh and Comilla using LR, ANNs and HSVR. A comparative study is conducted to examine the performance of each technique results. 
Table 5-Surface Level Features

\begin{tabular}{|c|l|}
\hline Feature Number & Description \\
\hline 1 & Mean sea level pressure \\
\hline 2 & Surface sea level pressure \\
\hline 3 & Surface airflow strength \\
\hline 4 & Surface meridional velocity \\
\hline 5 & Surface vorticity \\
\hline 6 & Surface wind direction \\
\hline 7 & Surface divergence \\
\hline 8 & Near surface relative humidity \\
\hline 9 & Surface specific humidity \\
\hline 10 & Mean temperature at $2 \mathrm{~m}$ \\
\hline
\end{tabular}

\section{Comilla station}

After the running of the stepwise linear regression the Equation (41) was obtained. The optimum number of neurons for hidden layer in neural network is 2 . The optimum setting for SVR is as $\epsilon=.001, C=23.32$ and $\sigma=3.41$. From the values of RMSE and R2-adj on it can be concluded that the HSVR is more reliable technique for downscaling in this station. Results are shown in Table 5 .

$$
y=0.28 * F_{\text {surf }_{3}}+0.26 * F_{\text {surf }_{5}}+.81 * F_{\text {surf }_{9}}-.64 * F_{\text {surf }_{10}}-.455
$$


Table 6-Comparative results of surface features for Comilla station

\begin{tabular}{|l|c|c|c|}
\cline { 2 - 4 } \multicolumn{1}{c|}{} & LR & ANN & HSVR \\
\hline R2 & 0.487 & 0.478 & 0.595 \\
\hline R2-adj & 0.340 & 0.329 & 0.479 \\
\hline MSE & 20790.806 & 21536.484 & 17315.515 \\
\hline RMSE & 144.190 & 146.753 & 131.588 \\
\hline Bias & 1165.788 & 1501.866 & 1322.757 \\
\hline
\end{tabular}

\section{Dhaka station}

After the running of the stepwise linear regression the Equation (42) was obtained. The optimum number of neurons for hidden layer in neural network is 2.The optimum setting for SVR is as $\epsilon=.001, C=0.48$ and $\sigma=0.16$.From the values of RMSE and R2-adj it can be concluded that the HSVR is more reliable technique for downscaling in this station. Results are shown in Table 7.

$y=-0.34 * F_{\text {surf }_{4}}-0.51 * F_{\text {surf }_{8}}+1.23 * F_{\text {surf }_{9}}-.69 * F_{\text {surf }_{10}}-0.50$

Table 7-Comparative results of surface features for Dhaka station

\begin{tabular}{|l|c|c|c|}
\cline { 2 - 4 } \multicolumn{1}{c|}{} & LR & ANN & HSVR \\
\hline R2 & 0.703 & 0.673 & 0.709 \\
\hline R2-adj & 0.610 & 0.571 & 0.618 \\
\hline MSE & 7913.045 & 9136.456 & 7719.496 \\
\hline RMSE & 88.955 & 95.584 & 87.861 \\
\hline Bias & -796.233 & -1180.258 & 317.035 \\
\hline
\end{tabular}

\section{Mymensingh station}

After the running of the stepwise linear regression the Equation (43) was obtained. $y=0.31 * F_{\text {surf }_{1}}+0.20 * F_{\text {surf }_{3}}-0.06 * F_{\text {surf }_{6}}-0.66 * F_{\text {surf }_{8}}+1.95 * F_{\text {surf }_{9}}-1.24 * F_{\text {surf }_{10}}-.38$

The optimum number of neurons for hidden layer in neural network is 6 . The optimum setting 
for SVR is as $\epsilon=.001, C=67.01$ and $\sigma=1$.16. From the values of RMSE and R2-adj it can be concluded that the HSVR is more reliable technique for downscaling in this station. Results are shown in Table 8.

Table 8-Comparative results of surface features for Mymensingh station

\begin{tabular}{|l|c|c|c|}
\cline { 2 - 4 } \multicolumn{1}{c|}{} & LR & ANN & HSVR \\
\hline R2 & 0.663 & 0.660 & 0.713 \\
\hline R2-adj & 0.558 & 0.554 & 0.623 \\
\hline MSE & 11620.199 & 10541.092 & 7687.767 \\
\hline RMSE & 107.797 & 102.670 & 87.67991 \\
\hline Bias & -73.780 & -151.237 & 154.883 \\
\hline
\end{tabular}

\subsubsection{Model for the features at $500 \mathrm{~Pa}$}

Table 8represents the features 500Pa far from the sea level. In this section, these features are used to downscale precipitation in three stations of Dhaka, Mymensingh and Comilla using LR, ANNs and HSVR. A comparative study is conducted to examine the performance of each technique. Results are shown in Table 9.

Table 9- 500Pa Large Scale Features

\begin{tabular}{|c|l|}
\hline Feature Number & Description \\
\hline 1 & 500 hpa airflow strength \\
\hline 2 & 500 hpa zonal velocity \\
\hline 3 & 500 hpameridonia velocity \\
\hline 4 & 500 hpaveticity \\
\hline 5 & 500 hpadivergance \\
\hline 6 & 500 hpa wind direction \\
\hline 7 & 500 hpageopotential height \\
\hline 8 & Relative humidity at $500 \mathrm{hpa}$ \\
\hline
\end{tabular}




\section{Comilla station}

After the running of the stepwise linear regression the Equation (44) was obtained. The optimum number of neurons for hidden layer in neural network is 2 . The optimum setting for SVR is as $\epsilon=.001, C=11.85$ and $\sigma=26.12$. From the values of RMSE and R2-adj it can be concluded that the HSVR is more reliable technique for downscaling in this station.

$y=-0.33 * F_{500 p a f_{1}}+0.33 * F_{500 \text { af }_{4}}+0.13 * F_{500 p a f_{8}}-.58$

Table 10-Comparative results of 500pa features for Comilla station

\begin{tabular}{|c|c|c|c|}
\cline { 2 - 4 } \multicolumn{1}{c|}{} & LR & ANN & HSVR \\
\hline R2 & 0.404 & 0.346 & 0.580 \\
\hline R2-adj & 0.275 & 0.205 & 0.489 \\
\hline MSE & 24036.218 & 25926.904 & 17106.678 \\
\hline RMSE & 155.036 & 161.018 & 130.7925 \\
\hline Bias & 405.251 & 782.164 & 856.2134 \\
\hline
\end{tabular}

\section{Dhaka station}

After the running of the stepwise linear regression the Equation (45) was obtained. The optimum number of neurons for hidden layer in neural network is 2 . The optimum setting for $\mathrm{SVR}$ is as $\epsilon=.001, C=71.72$ and $\sigma=2.44$. From the values of RMSE and R2-adj it can be concluded that the HSVR is more reliable technique for downscaling in this station. Results are shown in Table 11.

$y=-0.42 * F_{500 \text { paf }_{1}}+0.18 * F_{500 \mathrm{paf}_{4}}+0.14 * F_{500 p a f_{5}}-0.62$ 
Table 11-Comparative results of 500pa features for Dhaka station

\begin{tabular}{|c|c|c|c|}
\cline { 2 - 4 } \multicolumn{1}{c|}{} & LR & ANN & HSVR \\
\hline R2 & 0.562 & 0.603 & 0.716 \\
\hline R2-adj & 0.459 & 0.510 & 0.649 \\
\hline MSE & 12457.214 & 10908.616 & 7354.510 \\
\hline RMSE & 111.612 & 104.444 & 85.758 \\
\hline Bias & -1436.664 & -1140.296 & 280.667 \\
\hline
\end{tabular}

\section{Mymensingh station}

After the running of the stepwise linear regression the following Equation (46) was obtained. The optimum number of neurons for hidden layer in neural network is 5 . The optimum setting for $\mathrm{SVR}$ is as $\epsilon=.001, C=71.72$ and $\sigma=2.44$. From the values of MSE and R2-adj it can be concluded that the HSVR is more reliable technique for downscaling in this station. Results are shown in Table 12.

$$
\begin{gathered}
y=-0.71 * F_{500 \text { paf }_{1}}+0.50 * F_{500 \text { paf }_{2}}+0.33 * F_{500 \text { paf }_{4}}+0.19 * F_{500 \text { paf }_{5}}+0.12 * F_{500 \text { paf }_{8}} \\
-0.62
\end{gathered}
$$

Table 12-Comparative results of 500pa features for Mymensingh station

\begin{tabular}{|c|c|c|c|}
\cline { 2 - 4 } \multicolumn{1}{c|}{} & LR & ANN & HSVR \\
\hline R2 & 0.478 & 0.491 & 0.634 \\
\hline R2-adj & 0.343 & 0.360 & 0.540 \\
\hline MSE & 16478.558 & 16227.306 & 10745.802 \\
\hline RMSE & 128.369 & 127.386 & 103.662 \\
\hline Bias & -1240.054 & -1386.111 & -336.331 \\
\hline
\end{tabular}




\subsubsection{Model for the features at $850 \mathrm{~Pa}$}

Table 13-850 Large Scale Features

\begin{tabular}{|c|c|}
\hline Feature Number & Description \\
\hline 1 & 850 hpa airflow strength \\
\hline 2 & 850 hpa zonal velocity \\
\hline 3 & 850 hpameridonia velocity \\
\hline 4 & 850 hpaveticity \\
\hline 5 & 850 hpadivergance \\
\hline 6 & 850 hpa wind direction \\
\hline 7 & 850 hpageopotential height \\
\hline 8 & Relative humidity at $850 \mathrm{hpa}$ \\
\hline
\end{tabular}

\section{Comilla station}

After the running of the stepwise linear regression the Equation (47) was obtained. The optimum number of neurons for hidden layer in neural network is 2 . The optimum setting for SVR is as $\epsilon=.001, C=15.04$ and $\sigma=1.55$. From the values of RMSE and R2-adj it can be concluded that the HSVR is more reliable technique for downscaling in this station. Results are shown in Table 14.

$$
y=-0.28 * F_{850 p a f_{1}}+0.40 * F_{850 \text { paf }_{2}}-0.51 * F_{850 p a f_{5}}+0.18 * F_{850 p a f_{8}}-0.46(47)
$$

Table 14-Comparative results of 850pa features for Comilla station

\begin{tabular}{|l|c|c|c|}
\hline & LR & ANN & HSVR \\
\hline R2 & 0.546 & 0.522 & 0.599 \\
\hline R2-adj & 0.448 & 0.419 & 0.512 \\
\hline MSE & 19607.983 & 20269.273 & 19233.151 \\
\hline RMSE & 140.029 & 142.370 & 138.687 \\
\hline Bias & 1954.459 & 1787.563 & 2451.614 \\
\hline
\end{tabular}




\section{Dhaka station}

After the running of the stepwise linear regression the Equation (48) was obtained. The optimum number of neurons for hidden layer in neural network is 2 . The optimum setting for SVR is as $\epsilon=.001, C=85.8$ and $\sigma=9.51$. From the values of RMSE and R2-adj it can be concluded that the HSVR is more reliable technique for downscaling in this station. Results are shown in Table 15.

$y=-0.26 * F_{850 p a f_{1}}-0.09 * F_{850 p a f_{4}}+0.51 * F_{850 p a f_{5}}+.43 * F_{850 p a f_{7}}-0.37(48)$

Table 15-Comparative results of 850pa features for Dhaka station

\begin{tabular}{|l|c|c|c|}
\cline { 2 - 4 } \multicolumn{1}{c|}{} & LR & ANN & HSVR \\
\hline R2 & 0.611 & 0.592 & 0.683 \\
\hline R2-adj & 0.519 & 0.496 & 0.608 \\
\hline MSE & 10371.923 & 10479.498 & 8177.597 \\
\hline RMSE & 101.843 & 102.369 & 90.430 \\
\hline Bias & -900.363 & -184.099 & -284.656 \\
\hline
\end{tabular}

\section{Mymensingh station}

After the running of the stepwise linear regression the Equation (49) was obtained. The optimum number of neurons for hidden layer in neural network is 3 . The optimum setting for SVR is as $\epsilon=.001, C=31.46$ and $\sigma=0.10$. Based on the values of RMSE and R2-adj, it can be concluded that the HSVR is a more reliable technique for downscaling in this station. Results are shown in

$y=-0.18 * F_{850 \mathrm{paf}_{1}}+0.25 * F_{850 \mathrm{paf}_{4}}-0.14 * F_{850 \mathrm{paf}_{5}}-.42 * F_{850 \mathrm{paf}_{7}}+0.16 * F_{850 \mathrm{paf}}-0.48$ (49) 
Table 16-Comparative results of 850 pa features for Mymensingh station

\begin{tabular}{|c|c|c|c|}
\cline { 2 - 4 } \multicolumn{1}{c|}{} & LR & ANN & HSVR \\
\hline R2 & 0.546 & 0.613 & 0.627 \\
\hline R2-adj & 0.429 & 0.513 & 0.531 \\
\hline MSE & 17224.264 & 13672.636 & 11503.708 \\
\hline RMSE & 131.241 & 116.930 & 107.255 \\
\hline Bias & 649.002 & 474.860 & 174.885 \\
\hline
\end{tabular}




\section{Chapter 4: Conclusion}

Global climate change is a major area of concern to public and climate researchers. The focus this study was to evaluate regression techniques appropriate for precipitation downscaling problem. This study compared Linear Regression (LR), Artificial Neural Networks (ANNs), Hybrid Support Vector Regression (HSVR) techniques to predict precipitation at three (Mymensingh, Comilla and Dhaka) stations in Bangladesh. The study utilized 26 atmospheric features identified by CCCSN. The metric used for comparing these techniques were $R^{2}, R_{a d j}^{2}$, MSE, RMSE and bias.

The raw data was grouped at surface level, $500 \mathrm{~Pa}$ and $850 \mathrm{~Pa}$ for data for each group data was split into three portion: calibration, validation and test in the ratio of 70,20 and 10, respectively. The performance of each model was compared to the performance of other models on the test data.

In Surface level model for city of Comilla, the $R^{2}$ in HSVR was higher than other techniques. The $R^{2}$ for ANNs was close to $R^{2}$ of LR. The bias term of HSVR was less than bias of other techniques. LR outperformed ANN in terms of bias. Surface level model for the city of Dhaka HSVR outperformed other techniques in terms of $R^{2}$ and RMSE and LR performed better compare to other techniques in term of bias . 
In Mymensingh city, the result of ANNs and LR represents an equal performance in terms of $R^{2}$ and RMSE, but the bias value indicates a better performance of ANNs compare to LR. HSVR outperformed both techniques in different terms.

For $500 \mathrm{~Pa}$ scenarios of Comilla, HSVR outperform other techniques in terms of $R^{2}$ and RMSE. LR outperforms other techniques in terms of bias. HSVR outperformed ANNs and LR in terms of $R^{2}$, RMSE and bias in Dhaka station at $500 \mathrm{~Pa}$. ANN showed a better result compared to LR. For 500 Pa scenarios of Mymensingh station, HSVR outperformed LR and ANNs in terms of $R^{2}$, RMSE and bias. In this station, ANN showed a better performance compared to LR.

In 850 Pa scenarios of Comilla, ANN outperformed HSVR and LR in terms of RMSE and bias, but the $R^{2}$ for HSVR was higher than LR and ANNs. For $850 \mathrm{~Pa}$ scenarios of Dhaka station, HSVR outperformed ANNs and LR in terms of $R^{2}$, MSE, although ANN showed a smaller bias value compared to other techniques. In Mymensingh city at $850 \mathrm{~Pa}$, HSVR outperformed LR and ANNs in terms of $R^{2}$ RMSE and bias. 


\section{References}

1. Abaurrea, J., \&Asín, J. (2005). Forecasting local daily precipitation patterns in a climate change scenario. Climate Research, 28(3), 183-197.

2. Beckmann, B. R., \&AdriBuishand, T. (2002). Statistical downscaling relationships for precipitation in the Netherlands and North Germany. International Journal of Climatology, 22(1), 15-32.

3. Bergant, K., \&Kajfež-Bogataj, L. (2005). N-PLS regression as empirical downscaling tool in climate change studies. Theoretical and Applied Climatology, 81(1-2), 11-23.

4. Boardman, M., \&Trappenberg, T. (2006, July). A heuristic for free parameter optimization with support vector machines. In Neural Networks, 2006. IJCNN'06. International Joint Conference on (pp. 610-617). IEEE.

5. Busuioc, A., Chen, D., \&Hellström, C. (2001). Performance of statistical downscaling models in GCM validation and regional climate change estimates: application for Swedish precipitation. International Journal of Climatology, 21(5), 557-578.

6. Cannon, A. J., \& Whitfield, P. H. (2002). Downscaling recent streamflow conditions in British Columbia, Canada using ensemble neural network models. Journal of Hydrology, 259(1), 136-151.

7. Carpenter, R. G. (1960). Principles and procedures of statistics, with special reference to the biological sciences. The Eugenics Review, 52(3), 172.

8. Cawley, G. C., Haylock, M. R., Dorling, S. R., Goodess, C., \& Jones, P. D. (2003, April). Statistical downscaling with artificial neural networks. In ESANN (pp. 167-172).

9. Chen, S. T., Yu, P. S., \& Tang, Y. H. (2010). Statistical downscaling of daily precipitation using support vector machines and multivariate analysis. Journal of Hydrology, 385(1), 1322.

10. Chih-Chung Chang and Chih-Jen Lin, LIBSVM : a library for support vector machines. ACM Transactions on Intelligent Systems and Technology, 2:27:1--27:27, 2011. Software available at http://www.csie.ntu.edu.tw/ cjlin/libsvm

11. Dibike, Y. B., \&Coulibaly, P. (2006). Temporal neural networks for downscaling climate variability and extremes. Neural Networks, 19(2), 135-144. 
12. Duda, R. O., Hart, P. E., \& Stork, D. G. (1999). Pattern classification. John Wiley \& Sons.

13. Eberhart, R. C., \& Kennedy, J. (1995, October). A new optimizer using particle swarm theory. In Proceedings of the sixth international symposium on micro machine and human science (Vol. 1, pp. 39-43).

14. Fowler, H. J., Blenkinsop, S., \& Tebaldi, C. (2007). Linking climate change modelling to impacts studies: recent advances in downscaling techniques for hydrological modelling. International Journal of Climatology, 27(12), 1547-1578.

15. Giorgi, F., Christensen, J., Hulme, M., Von Storch, H., Whetton, P., Jones, R., ...\&Semazzi, F. (2001). Regional climate information-evaluation and projections. Climate Change 2001: The Scientific Basis. Contribution of Working Group to the Third Assessment Report of the Intergouvernmental Panel on Climate Change [Houghton, JT et al.(eds)]. Cambridge University Press, Cambridge, United Kongdom and New York, US.

16. Girvetz, E. H., Zganjar, C., Raber, G. T., Maurer, E. P., Kareiva, P., \& Lawler, J. J. (2009). Applied climate-change analysis: the climate wizard tool. PLoS One, 4(12), e8320.

17. Grotch, S. L., \&MacCracken, M. C. (1991). The use of general circulation models to predict regional climatic change. Journal of Climate, 4(3), 286-303.

18. Hall, T., Brooks, H. E., \&Doswell III, C. A. (1999). Precipitation forecasting using a neural network. Weather and Forecasting, 14(3), 338-345.

19. Hellstrom, C., Chen, D., Achberger, C., \&Raisanen, J. (2001). Comparison of climate change scenarios for Sweden based on statistical and dynamical downscaling of monthly precipitation. Climate Research, 19(1), 45-55.

20. Huth, R. (1999). Statistical downscaling in central Europe: evaluation of methods and potential predictors. Climate Research, 13(2), 91-101.

21. Huth, R. (2002). Statistical downscaling of daily temperature in central Europe. Journal of Climate, 15(13), 1731-1742.

22. Huth, R., Kyselý, J., \&Dubrovský, M. (2003). Simulation of surface air temperature by GCMs, statistical downscaling and weather generator: higher-order statistical moments. StudiaGeophysicaetGeodaetica, 47(1), 203-216.

23. Huth, R. (2005). Downscaling of humidity variables: a search for suitable predictors and predictands. International journal of climatology, 25(2), 243-250. 
24. Jasper, K., Calanca, P., Gyalistras, D., \& Fuhrer, J. (2004). Differential impacts of climate change on the hydrology of two alpine river basins. Climate Research, 26(2), 113-129.

25. Kettle, H., \& Thompson, R. (2004). Statistical downscaling in European mountains: verification of reconstructed air temperature. Climate Research, 26(2), 97-112.

26. Kidson, J. W., \& Thompson, C. S. (1998). A comparison of statistical and model-based downscaling techniques for estimating local climate variations. Journal of Climate, 11(4), 735-753.

27. Kysely, J. (2002). Comparison of extremes in GCM-simulated, downscaled and observed central-European temperature series. Climate Research, 20(3), 211-222.

28. Lin, S. W., Ying, K. C., Chen, S. C., \& Lee, Z. J. (2008). Particle swarm optimization for parameter determination and feature selection of support vector machines. Expert Systems with Applications, 35(4), 1817-1824.

29. Murphy, J. (2000). Predictions of climate change over Europe using statistical and dynamical downscaling techniques. International Journal of Climatology, 20(5), 489-501.

30. Ojha, C. S. P., Goyal, M. K., \&Adeloye, A. J. (2010). Downscaling of precipitation for lake catchment in arid region in India using linear multiple regression and neural networks. Open Hydrology Journal, 4(1), 122-136.

31. Olsson, J., Uvo, C. B., Jinno, K., Kawamura, A., Nishiyama, K., Koreeda, N., ...\& Morita, O. (2004). Neural networks for rainfall forecasting by atmospheric downscaling. Journal of Hydrologic Engineering, 9(1), 1-12.

32. Ralston, A., \&Wilf, H. (1960). Mathematical methods for digital computers. John Wiley.

33. Rumelhart, D. E., Hinton, G. E., \& Williams, R. J. (1988). Learning representations by backpropagating errors. Cognitive modeling.

34. Sailor, D. J., Hu, T., Li, X., \& Rosen, J. N. (2000). A neural network approach to local downscaling of GCM output for assessing wind power implications of climate change. Renewable Energy, 19(3), 359-378.

35. Schoof, J. T., \& Pryor, S. C. (2001). Downscaling temperature and precipitation: A comparison of regression- based methods and artificial neural networks. International Journal of Climatology, 21(7), 773-790.

36. Sherrod, P. (2014). DTREG. http://www. dtreg. com (http://www. dtreg. com). 
37. Suykens, J. A., Vandewalle, J., \& De Moor, B. (2001). Optimal control by least squares support vector machines. Neural Networks, 14(1), 23-35.

38. Tatli, H., NüzhetDalfes, H., \&SibelMenteş, Ş. (2004). A statistical downscaling method for monthly total precipitation over Turkey. International Journal of Climatology, 24(2), 161180.

39. Tolika, K., Maheras, P., Vafiadis, M., Flocas, H. A., \&Arseni-Papadimitriou, A. (2007). Simulation of seasonal precipitation and raindays over Greece: a statistical downscaling technique based on artificial neural networks (ANNs). International Journal of Climatology, 27(7), 861-881.

40. Vapnik, V. (2000). The nature of statistical learning theory. Springer.

41. Wilby, R. L., \& Dawson, C. W. (2013). The statistical downscaling model: insights from one decade of application. International Journal of Climatology, 33(7), 1707-1719.

42. Yegnanarayana, B. (2009). Artificial neural networks. PHI Learning Pvt. Ltd. 


\section{Appendix}

Result of Comilla Station

\begin{tabular}{|c|c|c|c|}
\hline LR & ANN & HSVR & Actual \\
\hline 0 & 7.4919 & 0 & 0 \\
\hline 38.40995 & 4.431394 & 26.68918 & 0 \\
\hline 10.95342 & 0 & 21.75082 & 0 \\
\hline 225.7063 & 202.2992 & 204.5633 & 116 \\
\hline 395.2081 & 311.3735 & 320.8654 & 182 \\
\hline 431.9948 & 379.3444 & 512.9184 & 639 \\
\hline 406.0056 & \begin{tabular}{|l}
373.3253 \\
\end{tabular} & 449.9248 & 382 \\
\hline 360.1953 & 365.6328 & 368.6153 & 577 \\
\hline 344.3329 & 345.3186 & 320.9756 & 114 \\
\hline 161.269 & 193.5954 & 164.4801 & 134 \\
\hline 67.1821 & 54.39016 & 33.28611 & 0 \\
\hline 61.11085 & 5.169233 & 16.2496 & 0 \\
\hline 0 & 0 & 14.68669 & 0 \\
\hline 54.82758 & 2.332845 & 13.44536 & 0 \\
\hline 0 & 0 & 0 & 0 \\
\hline 236.7803 & 223.4991 & 185.3211 & 189 \\
\hline 333.0068 & 285.9164 & 228.2955 & 237 \\
\hline 462.0446 & 370.3777 & 477.2742 & 446 \\
\hline 337.4565 & 380.8558 & 345.7911 & 456 \\
\hline 286.6099 & 348.4904 & 292.014 & 230 \\
\hline 195.8975 & 313.1967 & 191.9974 & 98 \\
\hline 124.0254 & 178.1816 & 112.144 & 231 \\
\hline 0 & 27.04694 & 15.38518 & 0 \\
\hline 0 & 11.3045 & 16.75667 & 0 \\
\hline 23.95085 & 0.667379 & 13.51156 & 0 \\
\hline 0 & -4.01698 & 11.13109 & 0 \\
\hline 33.46734 & 15.16414 & 6.634551 & 0 \\
\hline 281.381 & 219.3297 & 228.2007 & 121 \\
\hline 304.0275 & 269.2382 & 246.3138 & 343 \\
\hline 445.9003 & 347.6506 & 521.0399 & 544 \\
\hline 443.0747 & 346.9743 & 518.4423 & 816 \\
\hline 359.3145 & 359.0128 & 387.8781 & 540 \\
\hline 217.32 & 294.0573 & 210.6202 & 428 \\
\hline 255.9528 & 223.0164 & 255.0374 & 533 \\
\hline 32.38737 & 70.16078 & 35.13118 & 28 \\
\hline 6.055585 & 3.154961 & 4.34259 & 0 \\
\hline 0 & 1.706289 & 0 & 0 \\
\hline
\end{tabular}




Result of Comilla Station (cont'd)
\begin{tabular}{|c|c|c|c|}
\hline LR & ANN & HSVR & Actual \\
\hline 0 & 0 & 13.17921 & 0 \\
\hline 0 & 0 & 7.814551 & 0 \\
\hline 145.8676 & 162.8833 & 39.34804 & 0 \\
\hline 224.7175 & 241.2593 & 161.6533 & 53 \\
\hline 461.9884 & 373.2782 & 546.0972 & 717 \\
\hline 381.5965 & 358.2795 & 402.2044 & 595 \\
\hline 311.4961 & 313.2057 & 304.3034 & 810 \\
\hline 204.845 & 258.4074 & 200.5517 & 329 \\
\hline 118.4512 & 151.2181 & 105.0465 & 49 \\
\hline 56.10876 & 55.01283 & 35.68073 & 99 \\
\hline
\end{tabular}

Results for Dhaka Station

\begin{tabular}{|c|c|c|c|}
\hline LR & ANN & HSVR & Actual \\
\hline 226.9091 & 218.6896 & 315.623 & 414 \\
\hline 344.787 & 349.3528 & 340 & 323 \\
\hline 341.684 & 339.89 & 328.1558 & 380 \\
\hline 336.0109 & 348.1331 & 313.1402 & 269 \\
\hline 260.5191 & 266.0759 & 251.7338 & 296 \\
\hline 158.315 & 150.7382 & 149.2242 & 300 \\
\hline 72.7099 & 64.97926 & 58.44648 & 0 \\
\hline 21.66335 & 24.29814 & 26.59614 & 0 \\
\hline 0 & 2.854333 & 38.54991 & 10 \\
\hline 0 & 2.720116 & 39.74836 & 42 \\
\hline 31.8439 & 28.59713 & 37.4208 & 109 \\
\hline 180.0084 & 167.4901 & 200.6018 & 274 \\
\hline 291.1107 & 289.7411 & 300.6371 & 272 \\
\hline 347.6761 & 356.0117 & 312.503 & 168 \\
\hline 348.9662 & 354.3548 & 380.0383 & 356 \\
\hline 341.4519 & 343.1559 & 280.3275 & 188 \\
\hline 276.1385 & 279.7307 & 294.4424 & 320 \\
\hline 171.7293 & 165.5104 & 126.1096 & 82 \\
\hline 59.60113 & 54.04271 & 50.04636 & 9 \\
\hline 7.416278 & 13.04379 & 18.03288 & 35 \\
\hline 16.49892 & 19.14078 & 14.6789 & 0 \\
\hline 0 & 1.548599 & 0 & 15 \\
\hline 23.4128 & 18.21724 & 37.04616 & 81 \\
\hline 190.8914 & 186.2955 & 135.714 & 104 \\
\hline 295.3557 & 297.9235 & 293.9117 & 154 \\
\hline & & & \\
\hline
\end{tabular}


Results for Dhaka Station (Cont'd)

\begin{tabular}{|c|c|c|c|}
\hline LR & ANN & HSVR & Actual \\
\hline 360.4496 & 361.9288 & 307.2152 & 514 \\
\hline 339.8575 & 347.0915 & 331.5223 & 136 \\
\hline 325.9468 & 335.2291 & 316.0104 & 346 \\
\hline 261.9377 & 264.7644 & 257.2453 & 258 \\
\hline 125.936 & 119.9553 & 172.3593 & 146 \\
\hline 53.76282 & 47.62211 & 19.58237 & 51 \\
\hline 0 & 0 & 15.87201 & 0 \\
\hline 0 & 0 & 37.84018 & 61 \\
\hline 195.7 & 182.112 & 177.2174 & 318 \\
\hline 228.8397 & 220.6717 & 310.1535 & 348 \\
\hline 362.8828 & 366.4358 & 335.2329 & 300 \\
\hline 346.7499 & 344.9664 & 325.1153 & 179 \\
\hline 328.9846 & 349.9435 & 354.5373 & 437 \\
\hline 276.2609 & 276.5543 & 262.8227 & 322 \\
\hline 149.89 & 143.0574 & 154.7874 & 253 \\
\hline 0 & 0 & 44.52219 & 13 \\
\hline 0 & 4.758717 & 40.62641 & 1 \\
\hline 17.93187 & 21.3467 & 47.72421 & 5 \\
\hline 149.2771 & 137.9367 & 79.85005 & 124 \\
\hline 327.1211 & 331.265 & 310.0757 & 637 \\
\hline
\end{tabular}

Results for Mymensingh Station

\begin{tabular}{|c|c|c|c|}
\hline ANNs & LR & HSVR & Actual \\
\hline 0.0 & 2.8 & 0.0 & 0 \\
\hline 7.5 & 8.2 & 0.0 & 0 \\
\hline 28.4 & 21.2 & 0.0 & 0 \\
\hline 0.0 & 0.0 & 9.7 & 0 \\
\hline 0.0 & 0.0 & 28.2 & 0 \\
\hline 16.1 & 46.9 & 10.6 & 0 \\
\hline 0.0 & 0.0 & 25.4 & 0 \\
\hline 1.7 & 0.0 & 0.0 & 4 \\
\hline 6.8 & 14.5 & 0.0 & 7 \\
\hline 55.2 & 100.6 & 0.0 & 10 \\
\hline 0.0 & 0.0 & 37.9 & 13 \\
\hline 0.0 & 0.0 & 14.7 & 19 \\
\hline 50.8 & 84.3 & 17.1 & 19 \\
\hline 13.8 & 25.1 & 23.2 & 20 \\
\hline 26.8 & 11.4 & 55.2 & 25 \\
\hline
\end{tabular}


Results for Mymensingh Station

(Cont'd)

\begin{tabular}{|c|c|c|c|}
\hline ANNs & LR & HSVR & Actual \\
\hline 46.3 & 42.3 & 9.8 & 31 \\
\hline 81.7 & 114.7 & 50.6 & 46 \\
\hline 0.0 & 0.0 & 31.1 & 49 \\
\hline 83.7 & 53.3 & 44.5 & 59 \\
\hline 144.3 & 145.9 & 54.8 & 74 \\
\hline 157.9 & 156.6 & 113.3 & 76 \\
\hline 225.2 & 216.5 & 129.4 & 101 \\
\hline 285.0 & 281.3 & 252.1 & 179 \\
\hline 135.9 & 187.4 & 111.4 & 189 \\
\hline 236.4 & 184.5 & 232.3 & 204 \\
\hline 352.7 & 410.4 & 405.6 & 211 \\
\hline 458.1 & 464.4 & 487.6 & 218 \\
\hline 334.8 & 280.0 & 287.8 & 237 \\
\hline 338.4 & 329.0 & 408.1 & 283 \\
\hline 250.1 & 235.1 & 268.7 & 297 \\
\hline 219.5 & 210.8 & 289.1 & 368 \\
\hline 369.6 & 352.0 & 297.7 & 386 \\
\hline 201.9 & 184.2 & 270.6 & 396 \\
\hline 288.1 & 227.0 & 377.6 & 409 \\
\hline 234.9 & 174.2 & 245.1 & 448 \\
\hline 377.9 & 354.6 & 422.7 & 451 \\
\hline 369.6 & 382.5 & 359.1 & 472 \\
\hline 416.7 & 411.1 & 516.4 & 488 \\
\hline 422.4 & 357.7 & 495.4 & 558 \\
\hline 416.3 & 387.1 & 446.7 & 598 \\
\hline 290.4 & 263.5 & 330.6 & 669 \\
\hline & & & \\
\hline
\end{tabular}

